\title{
Supporting Student Experience During the Pandemic and Beyond
}

\author{
Rebecca Sanderson, Rachel Spacey, Xiaotong Zhu and Rhianne-Ebony Sterling-Morris \\ University of Lincoln, United Kingdom
}

\begin{abstract}
This article reports the findings from a small-scale, qualitative and phenomenological institutional research project, undertaken during the COVID-19 pandemic, on the experiences of undergraduate students from groups who are traditionally under-represented in higher education in the United Kingdom. Documenting the first two phases of a longitudinal study carried out at one university in England, the over-arching research question investigated here using semi-structured interviews was: How has the ongoing COVID-19 pandemic impacted student experiences and learning at university? Key themes identified included worry, a sense of loss, feelings of connection and support, a sense of a new geography of campus life and students' need to feel "in the loop". Evidence of changes with longer-term implications were also found, namely, an evolution in the relationship between students and their institution. A series of suggestions are presented based on the findings aimed at mitigating some of the ongoing negative effects of the pandemic on students.
\end{abstract}

Keywords: Student engagement; COVID-19; student experience.

\section{Introduction}

As the COVID-19 pandemic swept the world, many higher education (HE) institutions were thrown into turmoil. With the implementation of infection control measures like social distancing and the restrictions to movement and social interaction known as 'lockdowns' to help contain the all too often deadly virus, universities found themselves facing severe challenges to the delivery of teaching and student support services and potentially disastrous consequences for their students' learning and post-graduation prospects (Raaper \& Brown, 2020). Working during this time of unprecedented change created an urgent need to understand the impact of this rapidly evolving environment on university students, and to identify ways to adapt to ensure they both survive and thrive in the post-pandemic world. Growing evidence is emerging that the pandemic's negative effects on HE may be particularly severe for students from 'equity' groups (Bartz, 2020; Montacute \& Holt-White, 2020). Despite the "ethical imperative" (Bouchey et al, 2021, p. 38) to provide equal access to student support and online learning for all students, the specific support needs of some student groups during the pandemic have not yet received sufficient attention from researchers (Raaper \& Brown, 2020). The work reported here begins to address that gap.

This article reports the results of a small-scale qualitative study of the experiences of undergraduate students at one university in England who identified with characteristics of groups recognized by the UK HE regulator as typically under-represented in HE (Office for Students, 2020a). Several of these groups, including students with one or more disabilities and students with low socioeconomic status, have been identified as equity groups by other countries around the world (Salmi, 2018). This study was completed during the COVID-19 pandemic and the associated period of closures and restrictions which began in March

Except where otherwise noted, content in this journal is licensed under a Creative Commons Attribution 4.0 International Licence. As an open access journal, articles are free to use with proper attribution. ISSN: 2205-0795 
2020, implemented by the UK government in response to this public health crisis. The over-arching research question investigated here was: How has the ongoing COVID-19 pandemic impacted on student experiences and learning at university?

\section{Research Approach and Methodology}

This article describes the results of Phase I and II of a longitudinal study (with Phase III planned for May 2021, towards the end of the final semester of the UK academic year). Following receipt of ethical approval from the university ethics committee (Ref: 2019-0579 and 2020-0579), recruitment of participants was carried out with the aid of the Students' Union (SU)'s social media accounts and by approaching members of existing student consultation groups who had previously given consent to be contacted regarding participation in institutional research.

For purposes of anonymity, the participants are identified using the labels 'P1', 'P2' and so on. They were mostly returning undergraduate students and just one new university entrant. Fifteen students took part in total, 11 in Phase I and eight in Phase II. Four of the participants (P1, P2, P3 and P4) took part in both phases and participants received a £10 e-voucher in recognition of their contribution. Participants all self-identified as having intersecting characteristics associated with "educational disadvantage" defined here as characteristics associated with low HE participation, or less favourable outcomes in HE attainment or progression to postgraduate study or graduate-level employment. These characteristics have been identified by the UK HE regulator and include economic disadvantage (as indicated by a low household income), having a disability, or being the first member of their family to attend university (Office for Students, 2020b, Office for Students 2020c). Some demographic characteristics of the participants are summarised as follows:

- 8 participants identified as female, 7 as male

- 9 had one or more physical disabilities or mental health conditions

- 10 were the first in their family to go to university

- 2 identified as being from a Black, Asian, or Minority Ethnic (BAME) group

- 2 were estranged from (had little or no contact with) their family

- 7 experienced economic disadvantage

- 1 was a mature student (over the age of 22 on entry to HE).

Phase I (Spacey at al., 2020) was carried out in May 2020 during the final semester of the academic year 2019/20 and focused on students' perceptions and experiences of the first UK lockdown period (March 26 - May 10, 2020). Phase II followed in November 2020 during the first semester of the new academic year 2020/21 prior to, and during, the second UK lockdown (November 5 - December 2, 2020). Both phases explored students' recent experiences of university life.

The researchers were guided by a commitment to exploring the lived experiences of the participants and the need to report rapidly to the institution's senior management and were both empowered and confined by institutional or 'insider' research (Trowler, 2011). Balancing the requirements for speed with maintaining ethical, robust and meaningful research was a challenge that required a pragmatic and adaptive methodology. Phenomenological research operates within an interpretive paradigm and "seeks to describe the essence of a phenomenon by exploring it from the perspective of those who have experienced it" (Neubauer et al., 2019, p. 91). The decision to pursue this broadly phenomenological approach was predicated on a wider social justice framework which sought to privilege the voices of these students, and a desire to understand the nature of the pandemic student experience. Drawing on van Manen (1990) and his manifesto for "hermeneutic phenomenology", participants were asked to reflect on their experiences of the previous weeks and to consider their feelings at the present moment and hopes and fears for the future.

Semi-structured interviews were chosen as a method since this is considered compatible with the phenomenological approach, allowing participants to talk about a subject "in their own way using their own words" (Matthews \& Ross, 2010, p. 221). The interviews were carried out using online meeting software Microsoft Teams. Each interview took between 30 and 50 minutes and was recorded using a digital recording device. Due to the nature of this institutional research project and the necessity for a swift turn-around in order to urgently respond to the rapidly changing external environment, full transcription of the audio recording was not carried out. As a pragmatic alternative, researcher notes made during the interviews were analysed directly along with the audio recordings. These were subsequently coded inductively and thematically (Braun \& Clarke, 2013), and then second coded with a view to maintaining some robustness to a research protocol which was somewhat constrained by 
circumstances. In line with the phenomenological approach the themes described below sought to identify "structures of the lived experience" (van Manen, 2017, p. 777) of the students, maintaining respect for the diversity of their experiences whilst viewing their accounts through a critical lens (Salamon, 2018). Their identification was supported by the researchers' use of bracketing, a technique of "phenomenological reduction" requiring the researchers to gain insight into the "essence" of a phenomenon through an iterative process of reflection throughout the research project (Fischer, 2009; Kvale \& Brinkmann, 2009). Participants were guided through a participant information sheet and consent form prior to the interview and received a participant debrief sheet post-interview. All participants elected to receive a summary of the report pertaining to the study and were invited to provide further feedback on findings and to participate in future phases of the study.

\section{Findings}

Six themes were identified through analysis of the interview notes:

1. Worry

2. Sense of loss

3. Feelings of connection and support

4. An emerging 'new geography' of the campus

5. Being 'in the loop'

6. Testing participants' relationship with the university.

Each is explored briefly in turn below.

\section{Worry}

The first theme to emerge from the analysis was "worry." Participants were worried about the health impacts of the pandemic on themselves and their families. P15 reported feeling "reluctant and nervous" about returning to university for the new academic year. Concerns about finances were expressed by several participants, many of whom were reliant on paid employment to fund their living costs during their studies but found employment opportunities limited by the pandemic. P6 had lost their job as a result of the pandemic and was struggling to pay rent: "I need ways to bring in money to survive." Some had considered withdrawing from university but felt that the upheaval of leaving and the uncertainty around the availability of employment and the course of the pandemic was likely to create more problems than staying. For P9: "withdrawing was a thought in the back of my mind but I shut it down", describing a lack of confidence in their employment prospects which they were attempting to address with support from the careers service. Some students in their third year rationalised that they did not have long left until they completed their course, so it was better to stay: “it crossed my mind... but I don't think I could drop out" (P1). Worries about the future were common amongst participants. Some worried about the impact of assessment changes (such as the cancellation of closed-book examinations) on their degree outcomes, or the wider impact of the crisis on their ability to fulfil their potential. P14 shared anxiety about grades: "I will be very surprised with how Semester A goes ... it will undoubtedly have had a negative effect on the overall outcome of the degree." There were also worries about employment prospects post-graduation, particularly for those who did not have a clear career plan or goal. The loss of opportunities for extra-curricular activities and work experience made some feel their employability was weakened and at the same time the students were aware of the challenges of securing graduate jobs at a time of economic uncertainty. Accessing support from the university careers service was perceived to be reassuring.

\section{Sense of Loss}

Loss was a particularly significant theme, with participants variably feeling an acute loss of control, motivation, financial security and/or student experience. Participants spoke about having a sense of loss of agency, with regulations and restrictions bringing a feeling of having to "do as you are told" and an impression that their wishes were not always being heard and acted upon. An example provided by one student described the University turning down a request endorsed by a majority of students in the class. This refusal was attributed to university policy and its impact illustrates the risk of students losing faith in systems and processes designed to support student engagement and capture student voice. 
There was evidence of resignation about the impact of the pandemic on the university experience: "I knew it wasn't going to be perfect" (P2), but differing needs and expectations in relation to the delivery of teaching were evident. Some participants would have preferred an online-only delivery so that they could remain at home or reduce their social contact with others for health reasons, while others craved the "traditional" academic experience which they had originally signed up for and felt supported their learning more effectively. P6 described feeling demotivated because they couldn't "pop in" to speak to a member of staff and was concerned about "bothering" tutors and lecturers as they worked from home (in fact a concern for the wellbeing of their tutors and lecturers was notable amongst participants across both phases of the study). The disruption to the rhythm and routine of the academy was a problem for P15 who found their mental health condition worsening:

Six weeks of staring at a wall ... It's harder to get yourself out of bed because I can't even leave the house... You just feel really unmotivated ... I've struggled ... without a routine that involves going out of the house.

Seven of the participants came from low-income families and the experience of financial precarity was notable given that they were unable to rely upon family for additional support and that some were facing a loss of income from paid work due to the lockdowns. P6 was pleased to receive financial support from the university but was "very aware of the fact that this is all I have."

\section{Feelings of Connection and Support}

Feelings of connection with, and obtaining support from, peers, tutors, student support services and the institution was the third theme identified. Most participants felt disconnected from other students in their classes at some point, often due to requirements to 'self-isolate' (remain at home and avoid contact with others due to having symptoms or having been in contact with someone who had been diagnosed with COVID-19) or due to government implementation of legal restrictions on social mixing or travelling through both phases of this study. The move to 'blended learning' (a mixture of online and face-to-face teaching) during Phase II meant smaller classes, social distancing and substantially less face-to-face teaching than pre-pandemic and this also contributed to a lessening of social bonds with classmates: "I do feel quite disconnected from other students" (P2). Another student felt that as a result of a reduction of interactions with lecturers early on in the pandemic their education had shifted towards a pedagogy which felt like "one-way teaching" (P3). Participants were cynical about social media as a substitute for in-person activities, placing higher value on emotional and practical support from university support services, personal and academic tutors, family and friends. One to one online sessions with student advice and student wellbeing services, and with tutors, were particularly positively received. However, there were suggestions of a potential longer-term impact on mental health in relation to the ongoing anxieties and from the social isolation. P1 commented in Phase II that despite increased opportunities to interact: "I don't feel like talking to anyone".

\section{An Emerging 'New Geography' of the Campus}

A sense of a new geography emerged from the accounts of the participants as the fourth theme. Some who would ordinarily have lived on campus were choosing to remain within their family home. P12 reluctantly returned home, feeling a loss of independence as a result, and a lack of privacy and suitable study space could be a challenge, while P8 said, "[it's] hard to have people in your space all the time." Living in the city was not without its issues, however, particularly in externally rented (nonuniversity) accommodation owned by private landlords operating outside of the regulatory oversight and internal complaints resolution processes of the institution. For example, P1 had returned home early as they were struggling to cope with anti-social behaviour by other residents in his accommodation, while across both phases participants were frustrated by poor internet connections and the impact of this on their ability to engage online, socially and academically. The significance of particular buildings was evident, particularly the university library and the SU building which offered vital services, resources, study space and interactions with peers and staff, and if anything, the pandemic seemed to heighten the importance of these places to the participants. Frustration about the accessibility and protocols for accessing these spaces was evident, while clarity and communication about changes as the pandemic progressed were valued.

\section{Being 'in the Loop'}

The fifth theme related to the effectiveness of university communications, and the importance placed on feeling well-informed or "in the loop" in a rapidly changing environment. Within the UK, the progress of the pandemic and the associated fluctuations 
in infection control measures had significant implications for universities, and the effectiveness of communications seemed strongly linked to the satisfaction of the participants with the university's response. Email messages to students following quickly after government announcements or informing students about relevant changes to university policies which would affect them were reassuring, although in the early weeks of the pandemic "there was a lot of uncertainty" (P3). One participant who had dyslexia felt that a reliance on text-heavy emails was not easy for them to process. Messages from the Vice-Chancellor sent directly to students were described positively: "really nice... heart-warming" (P5) and seemed to send a message to students that their needs were being considered by senior leaders. However, sometimes a perceived excess of communications could feel overwhelming and contradictions between faculty-level and institution-level messages could create a sense of dissatisfaction and anxiety. For some students, such as the estranged students in Phase I, the communications sometimes felt too standardised and did not recognise their lived realities as young people who are no longer in communication with family, such as not having a home to return to during the first and second lockdowns.

\section{Testing Participants' Relationship with the University}

Finally, participants' narratives suggested an emerging tension in the relationship between students and their university. Through both phases of the study, participants maintained confidence in the institution: "I have faith they have done everything they could" (P14) despite the disruption to every aspect of their education. However, there was evidence of participants' growing scrutiny of the university's response to the pandemic over time. Several participants identified as a customer through both phases of the study, speaking of the high cost of tuition fees and "value for money" of their courses. This was not a straightforward consumer relationship with the institution and there was evidence of both a sense of empathy with, and reluctance to direct blame at academic staff or the institution itself. Most participants seemed to maintain an emotional connection to their university, linked to the visibility of and satisfaction with student support and SU services such as financial hardship funds, online counselling and deliveries of care packages, food and medications to self-isolating students. However, it was also clear that this relationship was fragile and that it was being tested by the pandemic. Several of the participants did feel disadvantaged by the necessary changes to teaching, assessment and extracurricular activities and their expectations of the institution's response remained high.

\section{Discussion: How has the Ongoing COVID-19 Pandemic Impacted Student Experiences and Learning?}

\section{Online Teaching and Assessment}

Within the generalised worry about the pandemic, students had articulated a sense of loss, and later, resignation in relation to their student experience. This was borne out in Phase I where there was some resistance to online delivery of teaching, but there was evidence of a greater acceptance of online and/or blended learning amongst the interviewees in Phase II. This aligned with the view of the wider student population as increased acceptance of online delivery was noted in a survey of more than 1000 undergraduate students (undertaken in November 2020) which found that satisfaction levels with online learning had grown since March of that year (Hewitt, 2020). This reaction may be due to the efforts universities made to manage expectations prior to students' return to university in September 2020. The increased capacity building in relation to digital pedagogy, combined with a growing acceptance of the pandemic as a medium-term rather than short-term phenomenon. The authors noted that although participants in Phase I expressed disappointment at the loss of face-to-face teaching, active assessment and critique of the quality of digital pedagogy did not manifest until Phase II. Perhaps students were subjecting their online lectures to greater scrutiny because in the absence of social opportunities, what else is there for students to do except study? "Covid-19 has thrown teaching quality into sharp relief, in the absence of all the other activities that would otherwise be filling up students' days" (Jackson, 2020, para. 24).

Access to adequate broadband and suitable study spaces was identified in this study and in other explorations of the pandemic student experience (Himat et al., 2020; Neuwirth, 2020;), and although this may impact all students it is likely to be a more significant challenge for students from equity groups. Inequalities in access to online teaching have been identified as a concern amongst school leaders (Trinidad, 2021) and in the context of HE a survey commissioned by the UK regulator found "a significant number of students whose access to remote education is being disrupted - sometimes severely - by poor access to core digital infrastructure" (Office for Students, 2020d, np), setting up a review of students' digital poverty as a result. Social mobility charity the Sutton Trust commissioned a survey of UK HE students which found that students from lower 
socioeconomic groups were more likely to be impacted by poor internet access and suitable study space compared to other groups of students (Montacute \& Holt-White, 2020).

\section{Social and Psychological Wellbeing}

Requirements for self-isolation affecting both teaching staff and students and intermittent social distancing requirements during lockdowns left some participants at increased risk of experiencing feelings of disconnection and of becoming disengaged from their learning and from peers. Several studies have linked the pandemic to increasing the incidence and severity of issues with mental and physical health. Majumdar et al. (2020) in their study of students and office workers found links between changes to working practices resulting from social distancing and lockdowns with increased feelings of isolation, physical and mental health difficulties, and sleep disorders; similarly, Jackson (2020) identified negative impacts on the pandemic on mental health. Savage et al. (2020) in their study of UK HE students found behavioural changes, in particular, a reduction in physical activity due to requirements to self-isolate, were associated with an increase in perceived stress. In one study of doctoral student mental health and the impact of the pandemic, additional risk factors for increased levels of mental distress included identifying as female and having a disability (Byrom, 2020).

Several researchers have emphasised the importance of student support services, particularly mental health services, in mitigating the adverse effects of the pandemic upon student wellbeing (Khan et al., 2020; Morgan, 2020; Zhai \& Du, 2020). Indeed, most of the participants in this study had found engagement with support services helpful with regard to their mental health, therefore effective promotion of the services available, particularly signposting from personal tutors, is indicated.

\section{Hopes and Fears for the Future}

While in Phase I of this study a concern about the impact on degree outcomes was noted, in Phase II, anxieties about employability and an awareness of a potentially challenging future jobs market were more marked. A report from Universities UK (2020) seems to confirm the worries of students about future employment, stating that "all the indicators appear to suggest that the UK is going to face a severe and deep recession accompanied by sharp rise in unemployment" with the higher likelihood of graduates struggling to find jobs (p. 2). While the wider student population is concerned about the future, one recent study of student experience during the pandemic identified that students from working class backgrounds were more likely to be worried about this than middle class students. The former were also more likely to have returned home during the lockdown periods and so were less likely to have taken part in extra-curricular activities which may have enhanced their employment prospects (Montacute \& Holt-White, 2020).

\section{Student Satisfaction and Student Support}

Over the two phases of the study, it was clear that participant perceptions of communication were important indicators of their satisfaction and confidence in the institution. University communications with students at a time of crisis is critical (O'Shea \& Mou, 2021), and Byrom et al. (2020) found in relation to postgraduate research students during the pandemic, communications that are personal, timely, clear, honest, and regular appear to be the most effective. The regularity of communications is also important, and the steady flow of information about infection control measures and support via university email is critical (Sahu, 2020).

Digital accessibility, both in relation to the need for a fast, stable internet connection and the accessibility of the learning materials themselves, is important, particularly for students with a specific learning difference such as dyslexia. Institutional support services and the support of personal tutors were praised highly by participants for their role in mitigating the ongoing effects of a rapid transition to online learning. Additional support from family members included financial, practical or emotional support, and this highlights that for those students without access to family support (such as the estranged students in Phase I), the pandemic had "exacerbated" the challenges they face (Office for Students, 2020e, p.1). Even where family support is available, for those students who are first in their family to attend university (who are more likely to be from lower income groups) the pandemic creates particular challenges. Bono et al.'s U.S. COVID-19 study found that students whose parents had not entered HE "experienced worse academic and financial impacts due to the pandemic compared to their higherparent education peers" (2020, p. 52). 
Reputationally, universities continue to face challenges. Media coverage in the UK over the second half of 2020 presented a negative picture of universities and their treatment of students (Dickinson, 2020). More widely there is evidence that the pandemic has caused significant student dissatisfaction as illustrated in a recent UK survey in which 47 per cent of respondents indicated that they wanted a tuition fee reduction or refund as compensation for the disruption (Jackson, 2020). Given this emerging evidence and the ongoing negative media commentary describing a consumer-orientated relationship between HE students and institutions, the importance of listening and responding to student concerns cannot be overstated.

\section{Conclusion}

This small-scale, rapid, qualitative research explored the question 'How has the ongoing COVID-19 pandemic impacted student experiences and learning at university? amongst undergraduate students from groups who are traditionally under-represented in UK HE. Key themes identified included worry and loss, feelings of disconnection, a sense of a new geography of campus life, the importance of effective communications and tensions in the relationship between students and their institution. However, while the experiences of the participants in this study may resonate with the wider student population there are certainly indications from the grey literature, such as research from charities, that the pandemic has exacerbated the difficulties experienced by students already experiencing disadvantage, particularly in relation to access to suitable digital infrastructure and study space (Montacute \& Holt-White, 2020).

The limitations of the study include the small number of students who were interviewed, many of whom were self-selecting from a small subset of students who had already taken part in related research. None of the participants were from a care experienced background or had caring responsibilities, for example. Moreover, the study was undertaken at one university and the experiences of participants may not be a reflection of other UK based HE students or HE students in other countries. While the study contributes some understanding to the issues affecting students who are traditionally under-represented in HE during the pandemic, there is an urgent need for more research to better understand the difficulties faced by these groups in the pandemic and post-pandemic university.

Considering the evidence of this study the authors suggest the following points are considered by HE institutions adapting their support for students studying during the pandemic and beyond.

\section{Help Students to Feel Connected}

Students in this study found it harder to connect to others, and connections between course peers seemed to be particularly weakened by blended delivery. Other research suggests that changes to the student experience because of the pandemic makes it easier for students to become disconnected and isolated. Universities should try to identify at-risk students early and encourage engagement with support services and online one-to-one tutorials. Teaching strategies which maximise opportunities for peer interaction should be considered where appropriate, particularly for larger cohorts where peer to peer connections may be reduced.

\section{Support Students Studying Remotely}

Some students enjoyed the option of living on campus, though sometimes struggled with the challenges associated with online delivery such as poor internet speeds, lack of quiet space to work and limited access to resources and hardware. Others were happier working within their family home and would prefer an option to remain there but may experience similar challenges in relation to online learning. Universities and students unions can support students by improving knowledge of the extent and impact of unsuitable environments and internet access for students living at home or in private rented accommodation and enabling safe access to hardware, software, learning resources and study spaces. Recognition of, and sensitive responses to, individual circumstances in the context of assignment submission deadlines and class participation are recommended, and effective promotion of support services is vital.

\section{Recognise and Support Access to Significant Spaces on Campus}

Understanding the geography of your campus and wider locality from your students' perspective could support their experience and participation in university life. Some places on campus may have a special significance, for example for participants in this 
study, these were the university library and SU buildings. Confusion over if, and when, these physical spaces can be accessed may have a negative impact on students. Particular attention should be paid to identifying significant spaces and ensuring communications around access to those spaces is clear.

\section{Keep Students 'In the Loop'}

Participants in this study appreciated emotionally intelligent institutional communications which were timely and targeted to their situation, particularly when the external environment was unstable. Institution and programme level communications gave a sense of the institutional position in relation to the changing situation and the latter gave practical, tailored information of relevance to the individual student. However, too many communications felt overwhelming, and a focus on student needs is important when identifying which communications to send out and when. Speedy and personal responses from tutors and support staff at a time of high anxiety and uncertainty will be appreciated.

\section{Help Students to Feel Seen and Heard to Enable a Sense of Agency}

Existing mechanisms for student engagement may not be fit for purpose in the pandemic and post-pandemic university and these may need to be reviewed. Continuing to recognise the diversity of the student body by acknowledging the needs of different student groups can support all students, including mature students and those with disabilities, to feel heard and maintain some sense of belonging.

Anxiety was a feature of participants lives, both a generalised anxiety associated with the pandemic and specific worries relating to personal circumstances. Simply acknowledging student anxieties during the pandemic can be powerful (Byrom et al., 2020), and it can be useful to raise awareness of this amongst tutors and professional support staff. Some of the concerns identified such as fears about employment prospects should be proactively addressed by supporting students to develop strategies to navigate the pandemic and post-pandemic jobs market.

\section{Consider the Shifting Relationship Between Students and the Institution}

Media discourses and the changes to teaching and assessment practices may be linked to anxiety about degree outcomes and a shift towards a more consumer-focussed discourse amongst participants in this study. Universities should continue to support teaching staff to deliver the best possible online provision, communicate clearly about why changes to assessment practices are being made and ensure students less confident with new assessment formats are identified and directed to the appropriate support. Research suggests student dissatisfaction may be growing and a failure to proactively address student concerns may lead students to lose faith in their institution over time.

\section{Acknowledgements}

This research was supported by the University of Lincoln and was conducted following receipt of a favourable ethical opinion from the University of Lincoln Ethics Committee (Ref: 2019-0579 and 2020-0579). The authors would like to thank all of the students who participated in this research and shared their experiences with us. Thanks are also due to Professor John Sharp for his ongoing assistance with the project. 


\section{References}

Bartz, J. (2020). All inclusive?! Empirical insights into individual experiences of students with disabilities and mental disorders at German universities and implications for inclusive higher education. Education Sciences, 10(9), 223. http://dx.doi.org/10.3390/educsci10090223

Bono, G., Kresimir, R. \& Hescox, J. (2020). Stress and wellbeing in urban college students in the US during the Covid-19 pandemic: Can grit and gratitude help? International Journal of Wellbeing, 10(3), 39-57. https://www.internationaljournalofwellbeing.org/index.php/ijow/article/view/1331

Bouchey, B., Gratz, E., \& Kurland, S. (2021). Remote student support during COVID-19: Perspectives of chief online officers in higher education. Online Learning, 25(1), 28-40. https://doi.org/10.24059/olj.v25i1.2481

Braun, V. \& Clarke, V. (2013). Successful qualitative research. A practical guide for beginners. Sage.

Byrom, N. (2020). COVID-19 and the research community: The challenges of lockdown for early-career researchers. eLife; 9. https://elifesciences.org/articles/59634

Byrom, N., Jackman, P., Zile, A., James, E., Tyrell, K., Williams, C.J., Haughey, T., Sanderson, R., Priestley, M., \& Cogan, N. (2020). COVID 19: Suggestions to universities, supervisors and line managers from doctoral and early career researchers. SMARTEN. https://www.smarten.org.uk/suggestions-following-covid-research.html

Dickinson, J. (2020, October 7). Where are we now? Plus \& Partner briefing October 2020 [Conference session]. WonkHE@Home: The New Normal II, online.

Fischer, C. (2009). Bracketing in qualitative research: Conceptual and practical matters. Psychotherapy Research, 19(4/5), 583-590. https://doi-org/10.1080/10503300902798375

Hewitt, R. (2020). Students' views on the impact of Coronavirus on their higher education experience in 2020/21. HEPI and YouthSight. https://www.hepi.ac.uk/wp-content/uploads/2020/12/HEPI-Policy-Note-27-Students-views-on-the-impact-ofCoronavirus-on-their-higher-education-experience-in-2020-21-FINAL.pdf

Himat, A. N., Takal, M. H., \& Hakimi, M. F. (2020). Afghan students' satisfaction from online learning during COVID-19 at Kandahar University, Kandahar, Afghanistan. American International Journal of Social Science Research 6(1), 16-29. https://doi.org/10.46281/aijssr.v6i1.931

Jackson, A. (2020). The expectation gap: Students' experience of learning during Covid-19 and their expectations for next year. WonkHE. https://wonkhe.com/blogs/the-expectation-gap-students-experience-of-learning-during-covid-19-andtheir-expectations-for-next-year/

Khan, A., Sultana, S., Hossain, S., Tasdik Hasan, M., Uddin Ahmed, H., \& Sikder, T. (2020). The impact of COVID-19 pandemic on mental health \& wellbeing among home-quarantined Bangladeshi students: A cross-sectional pilot study. Journal of Affective Disorders, 277, 121-128. https://doi.org/10.1016/j.jad.2020.07.135

Kvale, S., \& Brinkmann, S. (2009). InterViews. Learning the craft of qualitative research interviewing (2 $2^{\text {nd }}$ ed.). Sage.

Majumdar, P., Biswas, A., \& Sahu, S. (2020). Covid-19 pandemic and lockdown: Cause of sleep disruption, depression, somatic pain and increased screen exposure of office workers and students of India. Chronobiology International, 37(8), 1191-1200. https://10.1080/07420528.2020.1786107

Matthews, B., \& Ross, L. (2010). Research Methods: A practical guide for the social sciences. Longman.

Montacute, R., \& Holt-White, E. (2020) COVID-19 and social mobility impact brief \#2: University access \& student finance. The Sutton Trust https://www.suttontrust.com/wp-content/uploads/2020/05/COVID-19-and-Social-Mobility-ImpactBrief-2.pdf

Morgan, M. (2020). An exceptional transition to higher education: Induction of new and returning students during the 'new normal' year. Advance HE. https://www.advance-he.ac.uk/knowledge-hub/exceptional-transition-higher-educationinduction-new-and-returning-students-during

Neubauer, B. E., Witkop, C. T., \& Varpio, L. (2019). How phenomenology can help us learn from the experiences of others. Perspectives on Medical Education, 8, 90-97. https://doi.org/10.1007/s40037-019-0509-2

Neuwirth, L. S., Jović, S., \& Mukherji, B. R. (2020). Reimagining higher education during and post-COVID-19: Challenges and opportunities. Journal of Adult and Continuing Education. https://doi.org/10.1177/1477971420947738

Office for Students. (2020a). Our approach to access and participation. https://www.officeforstudents.org.uk/advice-andguidance/promoting-equal-opportunities/our-approach-to-access-and-participation/the-challenge/

Office for Students. (2020b). Differences in student outcomes- further characteristics. https://www.officeforstudents.org.uk/media/3948d9a3-84b5-409b-8b11760a9e94c997/differences_in_student_outcomes_further_characteristics_november_2020.pdf

Office for Students (2020c). Transforming opportunity in higher education. https://www.officeforstudents.org.uk/media/2efcda44-8715-4888-8d63-42c0fd6a31af/transforming-opportunity-inhigher-education.pdf

Office for Students (2020d) 'Digital poverty' risks leaving students behind. https://www.officeforstudents.org.uk/news-blogand-events/press-and-media/digital-poverty-risks-leaving-students-behind/ 
Office for Students (2020e) Coronavirus briefing note. Note 3. Students without family support. https://www.officeforstudents.org.uk/media/f6061588-c602-4f04-a099-003ac984cdba/ofs-coronavirus-briefing-notestudents-without-family-support-24-july-2020.pdf

Raaper, R., \& Brown, C. (2020). The Covid-19 pandemic and the dissolution of the university campus: Implications for student support practice. Journal of Professional Capital and Community, 5(3/4), 343-349. https://doi.org/10.1108/JPCC06-2020-0032

Sahu, P. (2020). Closure of universities due to Coronavirus disease 2019 (Covid-19): Impact on education and mental health of students and academic staff. Cureus, 12(4), e7541. https://dx.doi.org/10.7759\%2Fcureus.7541

Salamon, G. (2018). What's critical about critical phenomenology? Journal of Critical Phenomenology 1(1), 8-17. https://doi.org/10.31608/PJCP.v1i1.2

Salmi, J. (2018). All around the world. Higher education equity policies across the globe. https://worldaccesshe.com/wpcontent/uploads/2019/02/All-around-the-world-Higher-education-equity-policies-across-the-globe-FINAL-COPY-2.pdf

Savage, M. J., James, R., Magistro, D., Donaldson, J., Healy, L. C., Nevill, M., \& Hennis, P. J. (2020). Mental health and movement behaviour during the Covid-19 pandemic in UK university students: Prospective cohort study. Mental Health and Physical Activity, 19, 100357. https://doi.org/10.1016/j.mhpa.2020.100357

O’Shea, M., \& Mou, L. (2021). Crisis messaging: How universities are communicating the pandemic. https://www.universityaffairs.ca/opinion/in-my-opinion/crisis-messaging-how-universities-are-communicating-thepandemic $/$

Spacey, R., Zhu, X., Sanderson, R., \& Sterling-Morris, R. (2020). Living on the edge: The impact of COVID-19 on underrepresented student groups in English higher education. IMPact. Scholarly research notices 2020. https://cpb-euw2.wpmucdn.com/blogs.lincoln.ac.uk/dist/c/8316/files/2020/10/IMPact-Short-Notice-Spacey-et-al.-2020-Covid.pdf

Trinidad, J. E. (2021) Equity, engagement, and health: school organisational issues and priorities during COVID-19. Journal of Educational Administration and History, 53(1), 67-80. https://doi.org/10.1080/00220620.2020.1858764

Trowler, P. (2011). Researching your own institution. British Educational Research Association. https://www.bera.ac.uk/publication/researching-your-own-institution-higher-education

Universities UK (2020). Supporting graduates in a Covid-19 economy. Universities UK. https://www.universitiesuk.ac.uk/policy-and-analysis/reports/Documents/2020/supporting-graduates-covid19-economyjune-2020.pdf

Van Manen, M. (2017). But is it phenomenology? Qualitative Health Research 27(6), 775-779. https://doi:10.1177/1049732317699570

Zhai, Y., \& Du, X. (2020). Addressing collegiate mental health amid COVID-19 pandemic. Psychiatry Research, 288, 113003. https://doi.org/10.1016/i.psychres.2020.113003

\section{Please cite this article as:}

Sanderson, R., Spacey, R., Zhu, X., \& Sterling-Morris, R-E. (2021). Supporting student experience during the pandemic and beyond. Student Success, 12(3), 96-105. https://doi.org/10.5204/ssj.1847

This article has been accepted for publication in Student Success. Please see the Editorial Policies under the 'About' section of the Journal website for further information.

Except where otherwise noted, content in this journal is licensed under a Creative Commons Attribution 4.0 International Licence. As an open access journal, articles are free to use with proper attribution. ISSN: 2205-0795 